\title{
Electrode material in electrochemical decolorization of dyestuffs wastewater: A review
}

\author{
Sanaa El Aggadi ${ }^{1, *}$, Ghizlan Kaichouh ${ }^{1}$, Zoubida El Abbassi ${ }^{1}$, Mohammed Fekhaoui $^{2}$ and Abderrahim EL Hourch ${ }^{1}$ \\ ${ }^{1}$ Materials, Nanotechnologies and Environment Laboratory, Department of Chemistry, Faculty of Sciences, Mohammed V University in \\ Rabat, 4 Avenue Ibn Battouta, BP:1014, Rabat, Morocco \\ ${ }^{2}$ Department of Zoology and Animal Ecology, Scientific Institute, Mohammed V University in Rabat, Av. Ibn Batouta, B.P 703, 10106, \\ Rabat, Morocco
}

\begin{abstract}
Textile wastewater contains a variety of contaminants that are known to be hazardous. Synthetic dyes are one of the hazardous pollutants in the textile industry that are resistant to the photo/bio degradation. They cannot be destroyed under conventional wastewater treatment. This document presents a review on the electrochemical treatment of wastewater containing synthetic organic dyes by anodic oxidation for environmental protection. The mechanisms of electrochemical oxidation in anodic oxidation processes are well explained. A large number of electrodes have been tested by this method. Therefore, this paper aims to summarize and discuss the most important and recent results available in the literature on anode application for the removal of synthetic dyestuffs. Finally, the prospects of the process for future research are suggested.
\end{abstract}

\section{Introduction}

The main sources of environmental pollution in the textile industry are dyeing and finishing. They require large volumes of water and, as a result, generate huge quantities of wastewater with high levels of contaminants [1,2]. The coloring matter is the primary problem because it creates an aesthetic problem and its color discourages the use of downstream wastewater [3,4]. Water transparency, aesthetic merit and gas solubility are affected by the presence of dyes, even in small quantities or concentrations [5]. As a result, dye effluents are carcinogenic, toxic, teratogenic and take a long time to be photo/bio-degraded by the environment itself [6]. An abundant literature has reported the characteristics and applications of the main methods for removing dyes from water including physico-chemical, chemical and biological oxidation, has been compiled in various critical reviews [7-10]. However, these methods are generally ineffective in removing color, expensive, and less adaptable to a wide range of dye wastewaters. Anodic oxidation processes are part of the new wastewater treatment technologies, especially when they are loaded with toxic and bio-resistant organic substances. The main advantages are that there is practically no consumption of chemicals and no sludge production. Another advantage is that the processes are generally carried out at room temperature and atmospheric pressure, which avoids volatilization and the release of non-degradable residues. This process aims to mineralize organic matter into $\mathrm{CO}_{2}$ or convert it into biocompatible compounds [11]. It should be noted that the electrode material is a crucial factor in the optimization of anodic oxidation conditions. More attention has been given to the exploration of new anode materials to improve current efficiency [12]. This document aims to increase the knowledge of anodic oxidation, its oxidation mechanism and some results of electrode materials used for electrochemical oxidation of dyes for wastewater treatment.

\section{Oxidation mechanisms}

The electrochemical oxidation of organic matter for wastewater treatment can be achieved in different ways which are shown in Figure 1. It has generally been noted that the nature of the electrode material, the experimental conditions and the composition of the electrolyte significantly influence the oxidation mechanism.
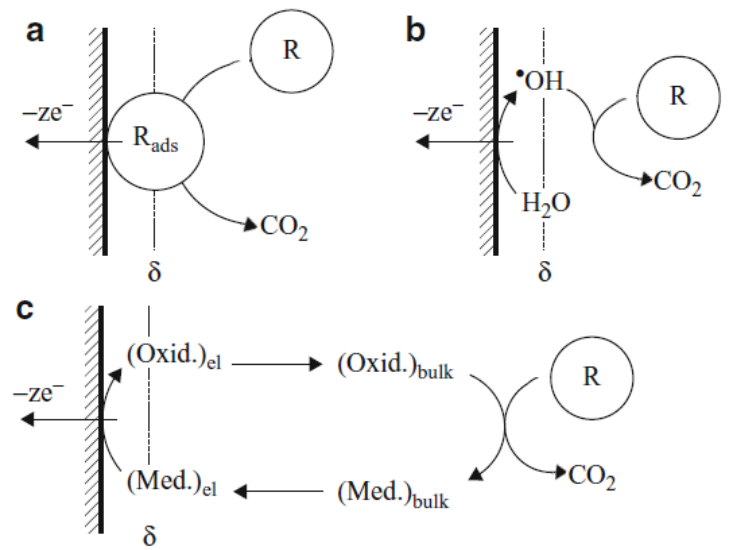

Fig.1 Scheme of the electrochemical processes for the removal of organic compounds (R): (a) direct electrolysis; (b) via hydroxyl radicals produced by the discharge of the water; (c) indirect electrolysis, where Med is the mediator and Oxid is the electrogenerated Oxidant [13].

* Corresponding author: sanaa elaggadi@um5.ac.ma 


\subsection{Direct oxidation}

Direct oxidation of pollutants on the anode surface is a complex process that consists of a series of simpler processes: transport of the pollutants from the bulk to the electrode surface, adsorption of the pollutant on the surface, direct electrochemical reaction by electron transfer to the pollutant, desorption of the products and transport of the oxidation products to the bulk. This process takes place without the intervention of substances other than the electron, which is a "clean reagent" [14].

$$
R_{a d s}-z e^{-} \rightarrow P_{a d s}
$$

However, it is not very efficient for the degradation of organic substances, principally because of the deactivation of the electrodes due to the formation of a polymer layer on the anode surface. But direct oxidation can lead to the formation of powerful oxidizing agents used in indirect oxidation processes $[15,16]$.

\subsection{Indirect oxidation}

In indirect oxidation, the organic pollutants are not directly exchanging electrons with the surface of the anode, but they do via certain electroactive species regenerated there, which act as an intermediary to shuttle between the electrode and the organic materials [17]. The main requirements for achieving high efficiencies in indirect oxidation processes are as follows:

(i) The production potential of the intermediate species must not be close to the potential of oxygen evolution;

(ii) The generation rate of the intermediate must be large;

(iii) The reaction rate of the intermediate species and the pollutant must be faster than the rate of any competing reaction;

(iv) The adsorption of the pollutant must be reduced to a minimum.

Oxidation mediators can be metallic redox couples or strong oxidizing chemicals.

\subsubsection{Metallic Redox Couple}

The indirect electrolysis that uses metallic couples such as $\mathrm{Ag}$ (II), $\mathrm{Co}(\mathrm{III}), \mathrm{Ce}$ (IV), and $\mathrm{Fe}$ (III) as redox reagents is called Mediated Electrochemical Oxidation (MEO). In acidic solutions, the metal ions are anodically oxidized from their stable oxidation state $\left(\mathrm{M}^{\mathrm{z}}\right)$ to the higher reactive oxidation state $\left(\mathrm{M}^{(\mathrm{z}+1)+}\right)$ in which they attack the other organic feed, decomposing it into carbon dioxide, insoluble inorganic salts and water [18] :

$$
\begin{gathered}
M^{z^{+}} \rightarrow M^{(z+1)+}+e^{-} \\
M^{(z+1)+}+\text { organics } \rightarrow M^{z^{+}}+\mathrm{CO}_{2}+\mathrm{H}_{2} \mathrm{O}
\end{gathered}
$$

\subsubsection{Oxidizing Chemicals}

The degradation of organic pollutants by indirect electrolysis can be achieved by generating in situ strongly oxidizing chemicals. Active chlorine is the most traditional and widely used oxidizing chemical generated by the anode and is the most widely used for wastewater treatment (Eq. 2).

$$
2 \mathrm{Cl}^{-} \rightarrow \mathrm{Cl}_{2}+2 e^{-}
$$

Depending on the $\mathrm{pH}$ value, chlorine remains in solution in the form of aqueous chlorine $(\mathrm{pH}<3.3)$ or disproportionate to hypochloric acid $(\mathrm{pH}<7.5)$ or hypochlorite ions $(\mathrm{pH}>7.5)$ [19]:

$$
\begin{aligned}
& \mathrm{Cl}_{2}+\mathrm{H}_{2} \mathrm{O} \rightarrow \mathrm{HOCl}+\mathrm{H}^{+}+\mathrm{Cl}^{-} \\
& \mathrm{HOCl} \rightarrow \mathrm{OCl}+\mathrm{H}^{+}
\end{aligned}
$$

Other strong oxidants, such as persulfate, perphosphate or percarbonate, can be used as mediators in the indirect electrochemical oxidation of organic materials. These compounds are obtained by anodic oxidation of sulphate, phosphate or carbonate ions present in solution as follows [18]:

$$
\begin{aligned}
& 2 \mathrm{SO}_{4}{ }^{2-} \rightarrow \mathrm{S}_{2} \mathrm{O}_{8}{ }^{2-}+2 e^{-} \\
& 2 \mathrm{CO}_{3}{ }^{2-} \rightarrow \mathrm{C}_{2} \mathrm{O}_{6}{ }^{2-}+2 e^{-} \\
& 2 \mathrm{PO}_{4}{ }^{3-} \rightarrow \mathrm{P}_{2} \mathrm{O}_{8}{ }^{4-}+2 e^{-}
\end{aligned}
$$

\subsection{Oxidation via Intermediates of Oxygen Evolution}

Oxidation of organic compounds can also be achieved by electrolysis at high anodic potentials in the water discharge zone due to the involvement of oxygen evolution intermediates [19]:

$$
\begin{aligned}
& \mathrm{M}+\mathrm{H}_{2} \mathrm{O} \rightarrow \mathrm{M}(\mathrm{OH})+\mathrm{H}^{+}+e^{-} \\
& R+\mathrm{M}(\mathrm{OH}) \rightarrow \mathrm{M}+\mathrm{CO}_{2}+\mathrm{H}_{2} \mathrm{O}
\end{aligned}
$$

Comninellis et al. [20] observed that the nature of the electrode material highly influences both the selectivity and the efficiency of the process and, in particular, different anodes favor partial and selective oxidation of pollutants, while others favor complete conversion to $\mathrm{CO}_{2}$. For the interpretation of these they suggested a complete model for the oxidation of organic matter at metal oxide electrodes with simultaneous oxygen evolution. They proposed a model for the oxidation of organic substances by hydroxyl radicals based on the existence of two types of anodes, the "active" and the "non-active". Examples of "active" anodes are $\mathrm{IrO}_{2}, \mathrm{Pt}$ and $\mathrm{RuO}_{2}$. On the other hand, $\mathrm{PbO}_{2}, \mathrm{SnO}_{2}$ and boron doped diamond (BDD) are examples of "non-active" anodes. A "non-active" electrode provides no active catalytic site for the adsorption of reagents and/or products from the aqueous environment. In this case, the anode serves only as an inert substrate, serving only as a well for electron removal [15]. 
Generally, the electrochemical oxidation of an aqueous effluent can follow two different routes:

(i) Electrochemical conversion, wherein the organic compounds are partially oxidized and transformed into more biodegradable reaction by-products, with further treatment still required, usually biological.

(ii) Electrochemical combustion, wherein the organic compounds are completely mineralized and transformed into water, carbon dioxide and other inorganic species, no additional purification being necessary [21-23].

\section{Electrode materials}

\subsection{Boron-Doped Diamond (BDD)}

The BDD based anode is a new electrode material that has received a lot of attention in the wastewater treatment field due to its large potential window, low background current, very low activity for the $\mathrm{O}_{2}$ evolution reaction and high anodic potential [24]. An additional advantage of using BDD electrodes for organic degradation is related to its inertness, which prohibits certain by-products or undesirable products from strongly adsorbing on the surface of the BDD. Most often, simply rinsing the BDD surface with a suitable solvent is sufficient to remove the adsorbed species [25]. Many dyes are successfully decolorized by anodic oxidation on the BDD electrode. Migliorini et al. [25] reported the anodic oxidation of Reactive Orange 16 (50 mg. $\left.\mathrm{L}^{-1}\right)$ azo dye on BDD electrode using titanium (Ti) as a substrate in supporting electrolyte of $0.1 \mathrm{M} \mathrm{K}_{2} \mathrm{SO}_{4}+0.1 \mathrm{M} \mathrm{H}_{2} \mathrm{SO}_{4}$. The color has completely vanished after $40 \mathrm{~min}$ of experimental time at $200 \mathrm{~mA} . \mathrm{cm}^{-2}$ of current density. Moreira et al. [26] reported the anodic oxidation with electrogenerated $\mathrm{H}_{2} \mathrm{O}_{2}\left(\mathrm{AO}-\mathrm{H}_{2} \mathrm{O}_{2}\right)$ of Sunset Yellow FCF (290 mg. $\left.\mathrm{L}^{-1}\right)$ azo dye using BDD electrode in $100 \mathrm{ml}$ of $0.05 \mathrm{M} \mathrm{Na}_{2} \mathrm{SO}_{4}$ at $\mathrm{pH} 3.0$. The $\mathrm{AO}-\mathrm{H}_{2} \mathrm{O}_{2}$ process allowed only a slow decolorization, reaching $88 \%$ decolorization in $360 \mathrm{~min}$. Faouzi et al. [27] reported the anodic oxidation of Alizarin Red S ( $5 \mathrm{mM}$ ) anthraquinone dye using $\mathrm{Si} / \mathrm{BDD}$ electrode in aqueous (1 $\left.\mathrm{M} \mathrm{H}_{2} \mathrm{SO}_{4}\right)$ solution. Complete color disappearance after 300 minutes of electrolysis time at $30 \mathrm{~mA} \cdot \mathrm{cm}^{-2}$ current density.

\subsection{Platinum}

Platinum represents the most widely used material in electrochemistry. Its high chemical resistance to corrosion as well as its stability in very aggressive environments have favored its use in the electrochemical degradation of pollutants [28]. Hamous et al. [29] reported the anodic oxidation of Orange $\mathrm{G}$ (75 mg. $\left.\mathrm{L}^{-1}\right)$ azo dye using platinum electrode. After 240 minutes of electrolysis, maximum color removal efficiency of $68.35 \%$ in $\mathrm{K}_{2} \mathrm{SO}_{4}$ $(0.1 \mathrm{M})$ and $100 \%$ in $\mathrm{KCl}(0.1 \mathrm{M})$ were obtained at 50 $\mathrm{mA} . \mathrm{cm}^{-2}$ current density. Da Costa Soares et al. [30] reported the anodic oxidation of Reactive Orange $16(0.4$ $\mathrm{mM})$ azo dye on platinum plate in aqueous solution $(0.05$ $\mathrm{M} \mathrm{Na}_{2} \mathrm{SO}_{4}$ ) at $\mathrm{pH} \mathrm{3.0.68 \%} \mathrm{color} \mathrm{removal} \mathrm{efficiency} \mathrm{was}$ obtained after 360 minutes of electrolysis at 33.3 $\mathrm{mA} . \mathrm{cm}^{-2}$ current density.

\subsection{Graphite}

Graphite electrode is very cheap and has a large surface area. It has therefore been widely used for the removal of organic substances in electrochemical reactors with threedimensional electrodes (e.g., packed bed, fluidized bed, carbon particles, porous electrode, etc.). Its use requires only minimal maintenance during operation and is not subject to corrosion in aqueous environments [28]. Different dyes are decolorized by anodic oxidation on the graphite anode. Bassyouni et al. [31] reported the anodic oxidation of acid brown 14 (100 mg. $\left.\mathrm{L}^{-1}\right)$ azo dye on graphite anode in aqueous $\left(1\right.$ g.. $\left.\mathrm{L}^{-1} \mathrm{NaCl}\right)$ solution at natural $\mathrm{pH}$ 6.0. Maximum color removal efficiency was obtained after 70 minutes of electrolysis at $79 \mathrm{~mA} . \mathrm{cm}^{-2}$ current density. Abdel-Aziz et al. [32] reported the anodic oxidation of methylene blue (50 ppm) azo dye on graphite anode in aqueous $\left(2.5\right.$ g. $\left.\mathrm{L}^{-1} \mathrm{NaCl}\right)$ solution at $\mathrm{pH}$ 3.0. A maximum color removal of $94 \%$ was achieved after 30 min treatment time at $42.55 \mathrm{~mA} . \mathrm{cm}^{-2}$ current density.

\section{4 $\mathrm{PbO}_{2}$}

$\mathrm{PbO}_{2}$ is an inexpensive electrode material that can be prepared quickly and easily as well as being relatively stable at high current density and over a wide $\mathrm{pH}$ range. This electrode can be used to generate ozone and to electrochemically oxidize organic contaminants [33,34]. Mukimin et al. [33] reported the anodic oxidation of Remazol Brilliant Blue $\mathrm{R}$ dye on $\mathrm{Ti} / \mathrm{PbO}_{2}$ anode in aqueous (4 g.L $\left.\mathrm{L}^{-1} \mathrm{NaCl}\right)$ solution at natural $\mathrm{pH}$ 7.0. A maximum color removal was attained in 60 min under constant potential $=5 \mathrm{~V}$ in alkaline solution. Bonyadinejad et al. [34] reported the anodic oxidation of Acid Orange 10 azo dye on $\mathrm{Ti} / \mathrm{PbO}_{2}$ anode in $\mathrm{Na}_{2} \mathrm{SO}_{4}$ as supporting electrolyte. The maximum color removal efficiency was obtained using the following optimal conditions: dye concentration $=100 \mathrm{mg} . \mathrm{L}^{-1}, \mathrm{pH}=12.05$, $\mathrm{Na}_{2} \mathrm{SO}_{4}=117.04 \mathrm{mM}$, and Current density $=73.64$ $\mathrm{mA} \cdot \mathrm{cm}^{-2}$. In these conditions, color was completely removed after 50 minutes of electrolysis.

\section{5 $\mathrm{RuO}_{2}$}

$\mathrm{RuO}_{2}$ anodes are dimensionally stable, and have an oxygen evolution potential of $2.0 \mathrm{~V}$. If wastewater contains a high concentration of $\mathrm{NaCl}$ (such as textile wastewater), $\mathrm{Ti} / \mathrm{RuO}_{2}$ anodes have shown better performance due to the production of several chlorinebased oxidants $\left(\mathrm{Cl}_{2}, \mathrm{HOCl}\right.$ and $\left.\mathrm{ClO}^{-}\right)$[35]. IsarainChávez et al. [36] reported the anodic oxidation of methyl orange $\left(30 \mathrm{mg} \cdot \mathrm{dm}^{-3}\right)$ azo dye on $\mathrm{Ti} / \mathrm{RuO}_{2}$ anode in aqueous $\left(0.05\right.$ mol.dm $\left.{ }^{-3} \mathrm{Na}_{2} \mathrm{SO}_{4}\right)$ solution at natural $\mathrm{pH}$ 7.0. A maximum color removal of $85 \%$ was attained in $240 \mathrm{~min}$ at $70 \mathrm{~mA} . \mathrm{cm}^{-2}$ current density.

\section{$3.6 \mathrm{SnO}_{2}-\mathrm{Sb}$}

$\mathrm{SnO}_{2}-\mathrm{Sb}$ electrode has a high efficiency for the oxidation of effluents containing organic compounds due to its strong oxygen evolution overvoltage, which promotes the 
generation of $\bullet \mathrm{OH}$ radicals which act in the indirect oxidation of the organic compounds on the electrode's surface [37]. Various dyes are decolorized by anodic oxidation on the $\mathrm{Ti} / \mathrm{SnO}_{2}-\mathrm{Sb}$ anode. Sarafraz et al. [38] reported the anodic oxidation of Acid Orange 10 (100 mg. $\left.\mathrm{L}^{-1}\right)$ azo dye on $\mathrm{Ti} / \mathrm{SnO}_{2}-\mathrm{Sb}$ anode in aqueous $(75 \mathrm{mM}$ $\mathrm{Na}_{2} \mathrm{SO}_{4}$ ) solution at $\mathrm{pH}$ 2.0. Maximum color removal efficiency was obtained after 50 minutes of electrolysis at $65 \mathrm{~mA} . \mathrm{cm}^{-2}$ current density. Sun et al. [39] reported the anodic oxidation of methylene blue $\left(100 \mathrm{mg} . \mathrm{L}^{-1}\right)$ azo dye on $\mathrm{Ti} / \mathrm{SnO}_{2}-\mathrm{Sb}$ anode in aqueous solution $(0.25 \mathrm{M}$ $\mathrm{Na}_{2} \mathrm{SO}_{4}$ ). $89.6 \%$ color removal efficiency was obtained after 240 minutes of electrolysis at $20 \mathrm{~mA} . \mathrm{cm}^{-2}$ current density.

According to the above results, the highly stable anodic materials such as $\mathrm{PbO}_{2}$ and mainly BDD electrodes can lead to a total discoloration of dye solutions due to the effective oxidation mediated especially with heterogeneous $\cdot \mathrm{OH}$ formed at the water discharge potentials.

\section{Conclusion}

Special attention has been given in the last decade to the implementation of electrochemical oxidation processes for the removal of aqueous organic pollutants. Although laboratory and pilot tests have been successful, industrial applications of these electrochemical methods are still limited due to the relatively high energy consumption. From our point of view, there are some main challenges that need to be addressed as a matter of priority to improve electrochemical oxidation so that it can be increasingly applied in the future:

(i) Reducing the price of electrodes, especially BDD;

(ii) Development of new electrode materials;

(iii) Improvement of median oxidation;

(iv) Use of renewable energy sources to power the processes.

\section{References}

1. M. Qamar, M. Saquib, M. Muneer, Desalination. 171, 185-193 (2005).

2. 2. J.J. Roxon, A.J. Ryan, Food Cosmet. Toxicol. 5, 367-369 (1967).

3. D. Brown, Ecotoxicol. Environ. Saf. 13, 139-147 (1987).

4. S. El Aggadi, N. Loudiyi, A. Chadil, O. Cherkaoui, A. El Hourch, Mediterr. J. Chem. 10, 82 (2020).

5. K.P. Sharma, S. Sharma, S. Sharma, P.K. Singh, S. Kumar, R. Grover, P.K. Sharma, Chemosphere. 69, 48-54 (2007).

6. X. Liu, J. Tian, Y. Li, N. Sun, S. Mi, Y. Xie, Z. Chen, J. Hazard. Mater. 373, 397-407 (2019).

7. E. Forgacs, T. Cserháti, G. Oros, Environ. Int. 30, 953-971 (2004).

8. V. Katheresan, J. Kansedo, S.Y. Lau, J. Environ. Chem. Eng. 6, 4676-4697 (2018).

9. D. Bhatia, N.R. Sharma, J. Singh, R.S. Kanwar, Crit.
Rev. Environ. Sci. Technol. 47, 1836-1876 (2017).

10. M. Rajabi, K. Mahanpoor, O. Moradi, RSC Adv. 7, 47083-47090 (2017).

11. S. Song, J. Fan, Z. He, L. Zhan, Z. Liu, J. Chen, X. Xu, Electrochim. Acta. 55, 3606-3613 (2010).

12. J. Sun, H. Lu, L. Du, H. Lin, H. Li, Appl. Surf. Sci. 257, 6667-6671 (2011).

13. W. Yun-Hai, C. Qing-Yun, L. Guo, L. Xiang-Li, Anodic Materials with High Energy Efficiency for Electrochemical Oxidation of Toxic Organics in Waste Water, in: Ind. Waste, InTech, 2012.

14. L. Feng, E.D. van Hullebusch, M.A. Rodrigo, G. Esposito, M.A. Oturan, Chem. Eng. J. 228, 944-964 (2013).

15. C.A. Martínez-Huitle, E. Brillas, Appl. Catal. B Environ. 87, 105-145 (2009).

16. M. Panizza, G. Cerisola, Electrochim. Acta. 51, 191199 (2005).

17. A. Fernandes, M.J. Pacheco, L. Ciríaco, A. Lopes, Appl. Catal. B Environ. 176-177, 183-200 (2015).

18. M. Panizza, G. Cerisola, Chem. Rev. 109, 6541-6569 (2009).

19. M. Panizza, Organic Pollutants, Direct and Mediated Anodic Oxidation, in: Encycl. Appl. Electrochem., Springer New York, 2014: pp. 1424-1428.

20. C. Comninellis, Electrochim. Acta. 39, 1857-1862 (1994).

21. C.A. Martínez-Huitle, S. Ferro, Chem. Soc. Rev. 35, 1324-1340 (2006).

22. Á. Anglada, A. Urtiaga, I. Ortiz, J. Chem. Technol. Biotechnol. 84, 1747-1755 (2009).

23. Y. Deng, J.D. Englehardt, Water Res. 40, 3683-3694 (2006).

24. N.A. Braga, C.A.A. Cairo, J.T. Matsushima, M.R. Baldan, N.G. Ferreira, J. Solid State Electrochem. 14, 313-321 (2010).

25. F.L. Migliorini, N.A. Braga, S.A. Alves, M.R.V. Lanza, M.R. Baldan, N.G. Ferreira, J. Hazard. Mater. 192, 1683-1689 (2011).

26. F.C. Moreira, S. Garcia-Segura, V.J.P. Vilar, R.A.R. Boaventura, E. Brillas, Appl. Catal. B Environ. 142143, 877-890 (2013).

27. A.M. Faouzi, B. Nasr, G. Abdellatif, Dye. Pigment. 73, 86-89 (2007).

28. M. Panizza, Importance of electrode material in the electrochemical treatment of wastewater containing organic pollutants, in: Electrochem. Environ., Springer New York, 2010: pp. 25-54.

29. H. Hamous, A. Khenifi, Z. Bouberka, Z. Derriche, Environ. Eng. Res. 25, 571-578 (2020).

30. I.C. da Costa Soares, D.R. da Silva, J.H.O. do Nascimento, S. Garcia-Segura, C.A. MartínezHuitle, Environ. Sci. Pollut. Res. 24, 24167-24176 (2017).

31. D.G. Bassyouni, H.A. Hamad, E.S.Z. El-Ashtoukhy, N.K. Amin, M.M.A. El-Latif, J. Hazard. Mater. 335, 
178-187 (2017).

32. M.H. Abdel-Aziz, M. Bassyouni, M.S. Zoromba, A.A. Alshehri, Ind. Eng. Chem. Res. 58, 1004-1018 (2019).

33. A. Mukimin, K. Wijaya, A. Kuncaka, Sep. Purif. Technol. 95, 1-9 (2012).

34. G. Bonyadinejad, M. Sarafraz, M. Khosravi, A. Ebrahimi, S.M. Taghavi-Shahri, R. Nateghi, S. Rastaghi, Korean J. Chem. Eng. 33, 189-196 (2016).

35. P. Kaur, J.P. Kushwaha, V.K. Sangal, Process Saf. Environ. Prot. 111, 13-22 (2017).

36. E. Isarain-Chávez, M.D. Baró, E. Rossinyol, U. Morales-Ortiz, J. Sort, E. Brillas, E. Pellicer, Electrochim. Acta. 244, 199-208 (2017).

37. J. Niu, D. Maharana, J. Xu, Z. Chai, Y. Bao, J. Environ. Sci. (China). 25, 1424-1430 (2013).

38. Sarafraz, M. Khosravi, G. Bonyadinejad, A. Ebrahimi, S.M. Taghavi-Shahri, Int. J. Environ. Health Eng. 4, 31 (2015).

39. Y. Sun, S. Cheng, Z. Mao, Z. Lin, X. Ren, Z. Yu, Chemosphere. 239, 124715 (2020). 